\title{
Air Transfer of Obstetric Emergencies to a Tertiary Care Center in Nepal
}

\author{
Katuwal $\mathbf{N}^{1}$, Rana $A^{1}$, Gurung $\mathbf{G}^{\mathbf{1}}$, Baral $\mathbf{J}^{\mathbf{1}}$ \\ ${ }^{1}$ Department of Obstetrics and Gynecology, Tribhuvan University Teaching Hospital, Kathmandu, Nepal.
}

Received: 17-Sep-2016; Accepted: 17-Dec-2016

Aims: This study was performed to review the places, indications, maternal-perinatal outcomes requiring emergency air transfer to a tertiary level referral center.

Methods: A hospital based descriptive study of one year duration, conducted in Tribhuvan University Teaching Hospital (TUTH), over a period of twelve months. All the women who were air transferred for pregnancy complications were enrolled.

Results: There were total 19 airlifted obstetric emergencies to TUTH over one year period: majority (68\%) from hilly areas and others (32\%) from mountain region. Out of them, referred cases were 11 [district hospital (5), healthpost (4); Primary Health Center (PHC) (2)]; and rest were from home (8). Two cases were abortion related; septic abortion (1) and incomplete abortion (1). There were three antepartum cases: pregnancy with meningoencephalitis (1), eclampsia (1) and bleeding placenta previa (1); maximum, eleven intrapartum cases, obstructed labor (6),labor dystocia (3), breech in labor (1) and undelivered second twin (1). Rest three were postpartum cases, one each of eclampsia, puerperal sepsis and retained placenta. Maternal morbidities were one each case of uterine rupture, acute kidney injury, retained placenta with PPH and vesicovaginal fistula that developed in the case of shoulder dystocia. Maternal mortality occurred in 2 cases, first women with antepartum eclampsia who had intracerebral bleed and second was a case of pregnancy with meningoencephalitis who later developed brain death. Regarding perinatal outcome 12/14 (86\%) had live birth and 2/14 (14\%) had IUFD upon arrival.

Conclusions: Air lift on personal expenditure, despite economic constraints has proven beneficial in our country's context with difficult geographical terrain and inadequate health services, whereas anticipation of any critical condition right in the beginning and timely transfer however could have been more advantageous.

Keywords: airlift; obstetric emergencies.

\section{INTRODUCTION}

Nepal has tremendous geographic diversity, ranging as low as $\mathbf{5 9}$ meters elevation in the tropical Terai to 90 peaks over 7,000 meters, including Earth's highest 8,848 meters Mount Everest. Nepal is topographically divided into three regions: the Himalayas to the north, the hills consisting of the Mahabharat range and the Chure Hills, and the Terai to the south. Annual Health Report of GoN 2070/71 inscribes that, there are as many as 1726 birthing and EmOC centers distributed over the five developmental regions. CEmOC services which includes the facility of caesarean section are currently provided in 56 districts. ${ }^{1}$ In Nepal access to health services even if available is complicated by difficult terrain, non-existent or poor condition of roads, unavailable transport facilities, unavailable skilled manpower thus women are seldom airlifted despite the cost factor to TU teaching hospital. The

\section{CORRESPONDENCE}

Dr Neeta Katuwal.

Department of Obstetrics and Gynecology, Tribhuvan University

Teaching Hospital

Email:neetakums@hotmail.com

Mobile number: +977-9841286974 benefit of appropriate medical transportation by air has been proven by numerous studies throughout the world, especially as regards of achieving appropriate timely medical intervention. ${ }^{2,3}$ Therefore the present study was carried out to review the places, indications, maternal-perinatal outcomes of women requiring emergency air transfer to TU Teaching Hospital.

\section{METHODS}

It is a prospective descriptive study conducted in Department of Obstetrics and Gynecology TUTH for one year duration in $2072 \mathrm{BS}$ (since $14^{\text {th }}$ April 2015), during which all the airlifted obstetric emergencies were enrolled. Permission from the Department of Obstetrics and Gynecology was taken before starting the study. Patients were explained about the purpose of the study and were included after taking informed consent. The places, indications requiring emergency air transfer to a tertiary level referral center were studied. Management of the patient, mode of delivery, maternal and perinatal outcomes were noted, women and babies were followed up until discharge. All collected data was filled in a predefined proforma. Data were analyzed using SPSS version 20. 


\section{RESULTS}

A total of 19 obstetric emergencies were airlifted to $\mathrm{TU}$ teaching hospital during the twelve months period. It accounted $0.3 \%(14 / 3911)$ of total deliveries in a year.Age of the women ranged from 17-43 years (mean 25.6 years).Parity ranged from $0-8$ with (mean 1.68). The mean gestational age of women delivering was 38 weeks $\pm 2.3 \mathrm{SD}$.

Majority women were airlifted from hilly areas $68 \%$ [ Khotang (6), Gorkha (4), Dhading (2), Bhojpur (1)] and from mountain region $32 \%$ [(Solukhumbu (3), Rasuwa (1),Sindhupalchowk (1) Sankhuwasabha (1)] (Figure 1).Eight (42\%) cases were airlifted directly from their home while others were referred from health care centers (58\%); district hospital 5 (26\%), heath post $4(21 \%)$ and $2(11 \%)$ cases from primary health care center (PHC) (Figure 2).

Figure 1: Map of Nepal showing regions and districts of Nepal from where women were airlifted

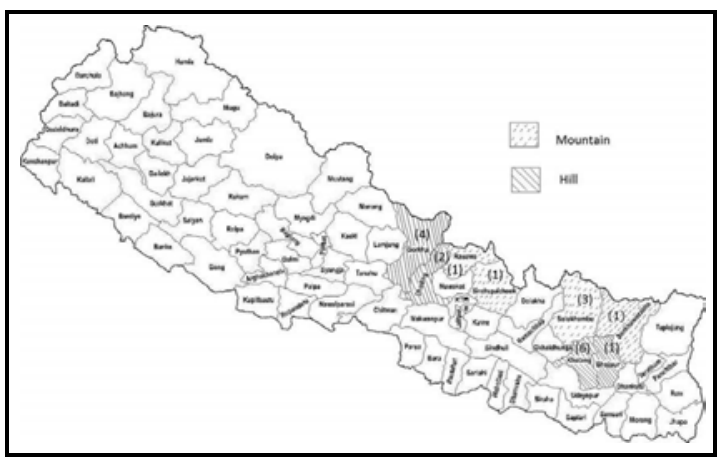

Figure 2: Sources of transfer

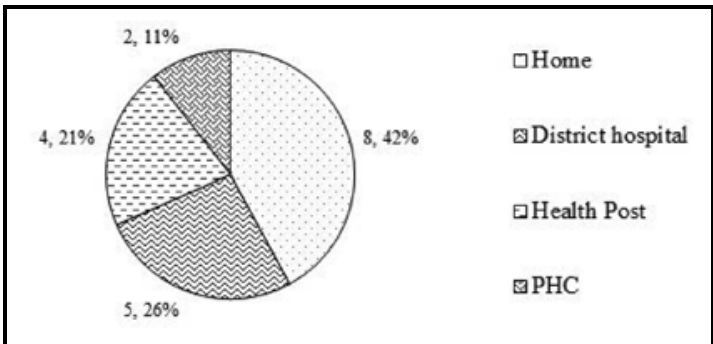

Eleven $(58 \%)$ of obstetric emergencies were air transferred due to difficult roads, far distance and unavailable transport and eight $(42 \%)$ due to inadequate health services (Figure3).
Figure 3: Social determinants of transfer

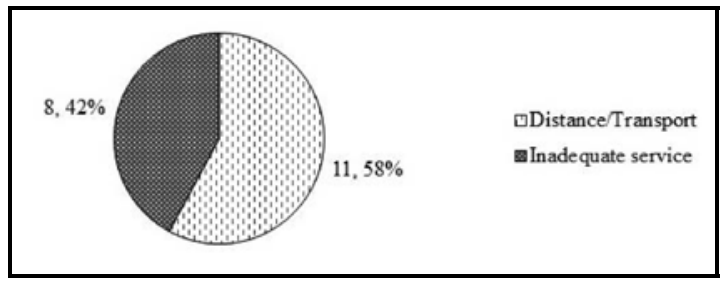

Among the obstetric emergencies, two cases were abortion related; septic abortion with AKI (1) and incomplete abortion with anemia (1). There were three antepartum cases: pregnancy with meningoencephalitis (1), eclampsia (1) and bleeding placenta previa (1) .Maximum, eleven intrapartum cases, obstructed labor 6: [with uterine rupture (1), shoulder dystocia with IUFD (1), cephalopelvic disproportion (4)]; others were footling breech in labor (1), undelivered second twin in transverse lie (1), labor dystocia (3).Rest three were postpartum cases, one each of eclampsia, puerperal sepsis and retained placenta (Figure 4).

Figure 4: Airlifted obstetric emergencies in tertiary care center

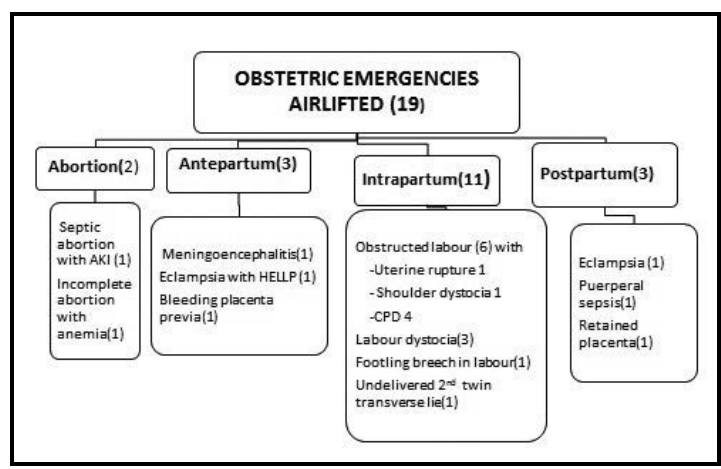

Figure 5: Mode of delivery

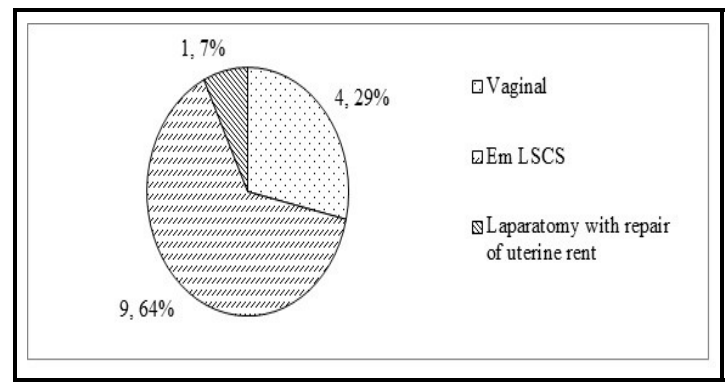

Majority nine (64\%)[ four cases of obstructed labor, one each case of antepartum eclampsia, footling breech, undelivered transverse second twin, bleeding 
placenta previa, woman diagnosed with brain death] had EmLSCS, four (29\%) [Three cases of labor dystocia, one case of shoulder dystocia with IUFD] had vaginal delivery and one case (7\%) underwent emergency laparotomy with repair of uterine rupture (Figure 5).

Maternal morbidities included uterine rupture(1), vesicovaginal fistula in a case of shoulder dystocia (1), acute kidney injury (1), retained placenta with PPH (1).Maternal mortality occurred in two cases, one in case of eclampsia with intracerebral bleed and second in case of pregnancy with meningoencephalitis with brain death(Figure 6).

Figure 6: Severe maternal morbidities and mortalities

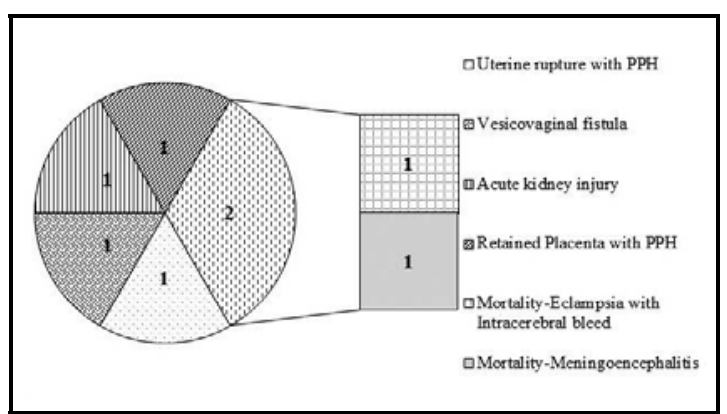

Majority of baby delivered were live birth, eleven $(85 \%)$ and out of them one baby had early neonatal death (NND) due to meconium aspiration syndrome (MAS) .Two babies(15\%)[One case of shoulder dystocia and one with uterine rupture] delivered were diagnosed IUFD on arrival (Figure 7).

Figure 6: Perinatal outcome

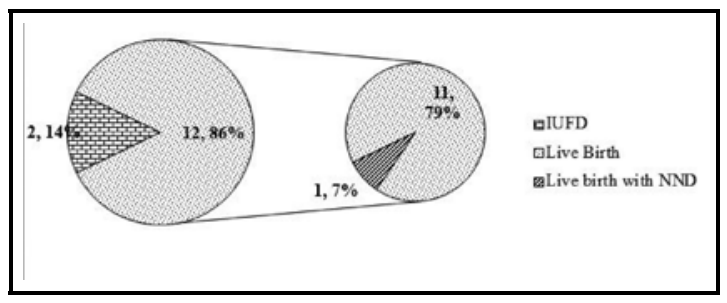

\section{DISCUSSION}

During the period of one year, there were total 19 airlifted obstetric emergencies. Majority were residents from hilly areas followed by mountainous region. Difficult terrain, inaccessibility to health care facilities and inadequate health services with urgency of situation were major social determinants for air transfer of these obstetric patients to TUTH.A study ${ }^{4}$ done in five remote districts of Nepal (Bajura, Rukum,
Gorkha, Rasuwa and Taplejung) on 'Access to MNCH services' showedthat as the distance to health facility increased utilization to services decreased, $31 \%$ of people lived more than eight hours travel from their district hospitals. Furthermore,shortage of human resources, skilled personnel like doctors and staff absenteeism was found as a barrier for health services.

Majority air transfer done in TU teaching hospital was during the intrapartum period for labor abnormalities like obstructed/prolong labor. In developed countries in-utero air transfer of high risk obstetric cases were done to tertiary neonatal care center for better perinatal outcome. ${ }^{6,7,8}$ This indicates poor utilization and accessibility of EmOC services, as shown in form of very low caesarean section rate of $1.4 \%$ in mountain areas compared with $3.7 \%$ in the hills and $5.8 \%$ in the Terai. ${ }^{9}$

Morbidities related to obstructed labor such as uterine rupture, shoulder dystocia and late complication like VVF could have been prevented with proper antenatal care with identification of these high risk women and timely referral to accessible institutional deliveries where caesarean section facility was available. Similar preventive methods of identification and prompt transfer have been highlighted in a seven year review of cases of uterine rupture in a tertiary care hospital. ${ }^{10}$

Two cases of post abortion complication, one for sepsis with renal failure and other for incomplete abortion with bleeding with anemia were referred from district hospital due to unavailability of blood products. There was one woman airlifted on fifth day of home delivery with retained placenta with $\mathrm{PPH}$ due to inaccessibility of health care facility. These all indicate towards poorly functioning and inaccessible emergency obstetric care in the hilly and mountain areas of Nepal. A study done under National Safe Motherhood Project ${ }^{11}$, in assessment of current EmOC services available in three districts (Baglung, Surkhet and Kailali) showed provision of safe blood and blood supply to be inadequate.

There were two maternal mortalities among the airlifted women to our center. First case was of woman who was transferred from district hospital with diagnosis of antepartum eclampsia with cardiac arrest post CPR, initially misdiagnosed as acid peptic disease and hence leading to delay in receiving care 
and hence, delay in referral. At the time of arrival, she had developed HELLP syndrome. After cardiac evaluation and PRP transfusion, she underwent EmLSCS. Baby was born with poor Apgar score with meconium stained liquor and had NND at dayl of life. Mother developed intracerebral bleed and had maternal mortality on second postoperative day.

Second mortality was in a pregnant woman at 33 weeks with acute meningoencephalitis who presented to our center after loss of consciousness at home for $12 \mathrm{hrs}$. She was admitted in ICU under mechanical ventilator. Baby was delivered by Em LSCS at 34 week after she was diagnosed brain death, with good perinatal outcome. Mother was declared dead after withdrawal of life support. Both the maternal mortalities could have been prevented if there was no delay in receiving care and timely management. Nepal's Maternal Morbidity and Mortality Study ${ }^{12}$ $2008 / 09$ found that $80 \%$ of maternal death cases at health facilities were admitted in a critical state, with $18 \%$ dying within 4 hours, 39\% within 12 hours and $53 \%$ within 24 hours of admission.

There were total of 11 live births including a baby of maternal brain death women who underwent EmLSCS at 34 weeks POG with good perinatal outcome. One early NND was in eclamptic mother who also had maternal mortality. Two IUFD cases of uterine rupture and shoulder dystocia each could have been prevented if proper ANC care would have identified CPD and managed appropriately. Studies ${ }^{13,14}$ have shown that delay in health seeking and preference to home deliveries due to cost of transport and health service, lack of services at local health center, distance to health facility were contributors to maternal mortality and newborn deaths in developing countries.

\section{CONCLUSION}

In country like Nepal with difficult terrain and inadequate health services, airlifting on personal expenditure despite economic constraints has proven beneficial in saving the life of mother and baby. Availability of emergency obstetric services which are acceptable, timely accessible and functional would be more advantageous.

\section{ACKNOWLEDGEMENTS}

To all the unit chief of Department of Obstetrics and Gynecology, TUTH under whom these women were managed.

\section{REFERENCES}

1. Department of Health Services. Annual Report 2070/71(2013/2014). Kathmandu: Government of Nepal, Ministry of Health; 2071.

2. Policy Resource and Education Paper (PREP) of the American College of Emergency Physicians (ACEP). Appropriate and safe utilization of helicopter emergency medical services. October 2012. Available from: http://www.acep.org/workarea/ DownloadAsset.aspx?id=104358

3. Wayne S. Aeromedicine- A regional approach. CME June 2004 Vol.22 No.6. Available from:www.ajol.info/index.php/ cme/article/download/43982/27500.

4. Regmi K, Upreti S, Iang DM. A study on access to maternal, neonatal, and child health services in remote areas of Nepal. FHD, World Bank, Nepal Health Sector Support Programme (NHSSP); October 2013.

5. Jony L, Baskett TF. Emergency air transport of obstetric patients. J Obstet Gynaecol Can. 2007; 29(5):406-8.

6. Low RB, Martin D, Brown C. Emergency air transport of pregnant patients:

7. the national experience. J Emerg Med. 1988;6(1):41-8.

8. Elliott JP, O'Keefe DF, Freeman RK. Helicopter transportation of patients with obstetric emergencies in an urban area. Am J Obstet Gynecol.1982;143(2):157-62.

9. Akl N, Coghlan EA, Nathan EA, Langford SA, Newnham JP. Aeromedical transfer of women at risk of preterm delivery in remote and rural Western Australia: Why are there no births in flight? Aust NZ J Obstet Gynaecol. 2012; 52(4):327-33.
10. HMG/MoH. Nepal Demographic and Health Survey 2011. Kathmandu:Ministry of Health and Population, New Era, USAID; 2012.

11. Sinha M, Gupta R, Gupta P, Rani R, Kaur R, Singh R. Uterine rupture: a seven year review at a tertiary care hospital in New Delhi, India. Indiand. 2016; 41(1):45-9.

12. Abbat J. Challenges to reducing maternal mortality: Experiences from three districts of Nepal supported by the Nepal Safer Motherhood Project-Kailali, Surkhet and Baglung. Kathmandu: FHD, Department of Health Services, Ministry of Health, HMGN, DFID;1999. P. 7-32.

13. Suvedi BK, Pradhan A, Barnett S, Puri M, Chitrakar S, Poudel P et al. Nepal Maternal Mortality and Morbidity Study 2008/2009: Summary of Preliminary Findings. Kathmandu: Family Health Division, Ministry of Health;2009.

14. Shrestha B. Maternal mortality in hilly districts of Nepal. Journal of Institute of Medicine.2009;31(2):7-13.

15. Gabrysch S, Campbell OM. Still too far to walk: literature review of the determinants of delivery service use. BMC Pregnancy Childbirth. 2009;9:34. 